\title{
Sperm DNA fragmentation
}

\author{
Jose G. Franco Jre ${ }^{1,2}$ \\ ${ }^{1}$ Center for Human Reproduction Prof. Franco Jr, Ribeirao Preto, SP, Brazil; ${ }^{2}$ Paulista Center for Diagnosis Research and Training, Ribeirao Preto, \\ SP, Brazil \\ Correspondence to: Prof. Jose G. Franco Jr. Center for Human Reproduction, Ribeirao Preto, SP, Brazil. Email: crh@crh.com.br. \\ Comment on: Agarwal A, Majzoub A, Esteves SC, et al. Clinical utility of sperm DNA fragmentation testing: practice recommendations based on \\ clinical scenarios. Transl Androl Urol 2016;5:935-50.
}

Submitted Jan 25, 2017. Accepted for publication Apr 24, 2017.

doi: 10.21037/tau.2017.05.07

View this article at: http://dx.doi.org/10.21037/tau.2017.05.07

I agree with Agarwal et al. (1) that sperm DNA fragmentation (SDF) should be included in the evaluation of male factor infertility, along with semen analysis.

Although there exist divergent views on this topic, our group has routinely employed SDF (TUNEL assay) and other methods for identification of sperm DNA damage (Chromomycin A3, MitoTracker Green, Annexin V) during the investigation of male factor infertility over the last 10 years. We call this global assessment sperm DNA integrity (SDI), and during this time we analyzed some clinical implications, as below.

(I) Are there age thresholds for increased SDI?

The effect of aging on SDF was evaluated in 2,178 semen samples. SDF deteriorated with aging (SDF: $\leq 35$ years, $14.7 \%$; $\geq 36$ years, $16 \% ; \mathrm{P}<0.05$ ), and this seems to be associated with mitochondrial damage (2). Sperm apoptosis, measured using Annexin V, is not correlated with aging (apoptosis: $\leq 35$ years, $19.1 \% \pm 8.0 \%$; $36-39$ years, $19.3 \% \pm 7.9 \%$; $\mathrm{P}>0.05$ ) (2). Evidence suggests that there are declines in semen quality and male fertility associated with increasing male age. Advanced paternal age has been implicated in a higher frequency of miscarriages, autosomal dominant diseases, aneuploidy, and other disorders. Advanced male age has also been correlated with infant mortality (3-5). One plausible explanation for these outcomes is that older men may have more sperm with damaged DNA. Chromatin damage has been associated with male infertility, conception problems, and difficulties to sustain a pregnancy. There is also evidence linking sperm DNA damage with the risk of mutations and birth defects (6-9). The age-related increase in sperm DNA damage suggests that delaying childbearing, not only for women but also for men, may jeopardize the couple's reproductive capacity.

(II) Does varicocele affect SDI?

SDI is considered a marker of male fertility potential. High levels of SDF have been significantly linked to lower rates of natural conception and assisted reproductive pregnancies $(1,10)$. Varicocele has been associated with increased levels of reactive oxygen species and decreased seminal antioxidant capacity, increased SDF and defective spermatogenesis in affected patients. A cross-sectional study was carried out with semen samples from 2,399 men, randomly selected from couples who attended an infertility clinic. A total of $16.3 \%(391 / 2,399)$ of the men had a varicocele (11). Physical examination was used to diagnose varicocele. Individuals with varicocele have increased SDF associated with an increase in abnormal mitochondrial activity and an increase in abnormal chromatin packaging (SDF with varicocele, $16.3 \% \pm 8.8 \%$; SDF without varicocele, 15.3\%; OR: 1.02, 95\% CI, 1.01-1.03, $\mathrm{P}=0.03)$ (11).

(III) Is overweight/obesity associated with a decrease in sperm quality and impaired SDI?

Obesity appears to have a negative influence on the male fertility and reproductive function overall. Overweight and obesity have been associated with significant reductions in the levels of total testosterone, free testosterone, and sex hormone- 
binding globulin, with elevated levels of estrogens (12-22). In addition, the build-up of suprapubic and inner fat may cause scrotal hyperthermia, which is a probable the cause of elevated oxidative stress $(13,18,23,24)$. Some studies have highlighted problems with sperm quality in patients with high body mass index (BMI), but the results are conflicting (12-26). SDI is another factor that may affect obese men; however, previous studies have shown controversial results regarding such an influence. BMI measures were carried out in a cohort of 1,824 men from couples who underwent infertility evaluations (27). High BMI negatively impacts sperm quality. In our study, high BMI was not associated with SDF, apoptosis, or protamination, but it was associated with increased mitochondrial damage.

Given the adverse consequences of obesity, the benefits of weight reduction should be discussed when counseling couples interested in fertility treatment. The exact mechanisms that mediate the effects of obesity on sperm mitochondrial damage require additional investigation. Possible medical actions would include counseling for weight reduction, antioxidants, and bariatric surgery.

Despite the clinical information acquired in recent years, important issues remains to be solved, as below:

(I) The methods employed for determining SDF or SDI use several technologies to evaluate different DNA-damaging processes. It is not known exactly where the DNA is damaged and the degree of pathophysiological importance of the damaged site. The limits of normality are variable, making it difficult to analyze the cases individually;

(II) Clinical interventions are not always conducted with the support of evidence-based medicine;

(III) Only with the development of more precise and specific methods for DNA damage assessment we will be able to clarify the many unsolved issues concerning SDF and male infertility.

\section{Acknowledgements}

None.

\section{Footnote}

Conflicts of Interest: The author has no conflicts of interest to declare.

\section{References}

1. Agarwal A, Majzoub A, Esteves SC, et al. Clinical utility of sperm DNA fragmentation testing: practice recommendations based on clinical scenarios. Transl Androl Urol 2016;5:935-50.

2. Baruffi R, Petersen CG, Mauri AL, et al. The effects of age on sperm DNA damage: an evaluation of 2,178 semen samples. Hum Reprod 2016;31:178-9.

3. Zhu JL, Vestergaard M, Madsen KM, et al. Paternal age and mortality in children. Eur J Epidemiol 2008;23:443-7.

4. Urhoj SK, Jespersen LN, Nissen M et al. Advanced paternal age and mortality of off- spring under 5 years of age: a register-based cohort study. Hum Reprod 2014;29:343-50.

5. Kovac JR, Ramasamy R, Dupree JM, et al. Words of wisdom. Re: Advanced paternal age and mortality of offspring under five years of age: a register-based cohort study. Eur Urol 2014;65:1222-3.

6. Wyrobek AJ, Eskenazi B, Young S, et al. Advancing age has differential effects on DNA damage, chromatin integrity, gene mutations, and aneuploidies in sperm. Proc Natl Acad Sci U S A 2006;103:9601-6.

7. Paul C, Robaire B. Ageing of the male germ line. Nat Rev Urol 2013;10:227-34.

8. Cassuto NG, Hazout A, Bouret D, et al. Low birth defects by deselecting abnormal spermatozoa before ICSI. Reprod Biomed Online 2014;28:47-53.

9. Hershko-Klement A, Sukenik-Halevy R, Biron Shental $\mathrm{T}$, et al. Intracytoplasmic morphologically selected sperm injection and congenital birth defects: a retrospective cohort study. Andrology 2016;4:887-93.

10. Tamburrino L, Marchiani S, Montoya M, et al. Mechanisms and clinical correlates of sperm DNA damage. Asian J Androl 2012;14:24-31.

11. Nicoletti A, Petersen CG, Mauri AL, et al. Semen parameters in men with varicocele: DNA fragmentation, chromatin packaging, mitochondrial membrane potential, and apoptosis. Hum Reprod 2016;31:i79.

12. MacDonald AA, Herbison GP, Showell M, et al. The impact of body mass index on semen parameters and reproductive hormones in human males: a systematic review with meta-analysis. Hum Reprod Update 2010;16:293-311.

13. Crujeiras AB, Casanueva FF. Obesity and the reproductive system disorders: epigenetics as a potential bridge. Hum 
Reprod Update 2015;21:249-61.

14. Hajshafiha M, Ghareaghaji R, Salemi S, et al. Association of body mass index with some fertility markers among male partners of infertile couples. Int J Gen Med 2013;6:447-51.

15. Hofny ER, Ali ME, Abdel-Hafez HZ, et al. Semen parameters and hormonal profile in obese fertile and infertile males. Fertil Steril 2010;94:581-4.

16. Håkonsen LB, Thulstrup AM, Aggerholm AS, et al. Does weight loss improve semen quality and reproductive hormones? Results from a cohort of severely obese men. Reprod Health 2011;8:24.

17. Leisegang K, Bouic PJ, Menkveld R, et al. Obesity is associated with increased seminal insulin and leptin alongside reduced fertility parameters in a controlled male cohort. Reprod Biol Endocrinol 2014;12:34.

18. Palmer NO, Bakos HW, Fullston T, et al. Impact of obesity on male fertility, sperm function and molecular composition. Spermatogenesis 2012;2:253-63.

19. Stewart TM, Liu DY, Garrett C, et al. Associations between andrological measures, hormones and semen quality in fertile Australian men: inverse relationship between obesity and sperm output. Hum Reprod 2009;24:1561-8.

20. Teerds KJ, de Rooij DG, Keijer J. Functional relationship between obesity and male reproduction: from humans to animal models. Hum Reprod Update 2011;17:667-83.

Cite this article as: Franco JG Jr. Sperm DNA fragmentation. Transl Androl Urol 2017;6(Suppl 4):S516-S518. doi: 10.21037/ tau.2017.05.07
21. Tunc O, Bakos HW, Tremellen K. Impact of body mass index on seminal oxidative stress. Andrologia 2011;43:121-8.

22. Vermeulen A, Kaufman JM, Deslypere JP, et al. Attenuated luteinizing hormone $(\mathrm{LH})$ pulse amplitude but normal LH pulse frequency, and its relation to plasma androgens in hypogonadism of obese men. J Clin Endocrinol Metab 1993;76:1140-6.

23. Fariello RM, Pariz JR, Spaine DM, et al. Association between obesity and alteration of sperm DNA integrity and mitochondrial activity. BJU Int 2012;110:863-7.

24. Jung A, Schill WB. Male infertility. Current life style could be responsible for infertility. MMW Fortschr Med 2000;142:31-3.

25. Campbell JM, Lane M, Owens JA, et al. Paternal obesity negatively affects male fertility and assisted reproduction outcomes: a systematic review and meta-analysis Reprod Biomed Online 2015;31:593-604.

26. Sermondade N, Faure C, Fezeu L, et al. BMI in relation to sperm count: an updated systematic review and collaborative meta-analysis. Hum Reprod Update 2013;19:221-31.

27. Oliveira JB, Petersen CG, Mauri AL, et al. Association between body mass index (BMI) and sperm quality or sperm DNA integrity. A large population study. Hum Reprod 2016;31:i79-80. 